\title{
Medical Image of the Week: Duodenal Obstruction Secondary to Superior Mesenteric Artery Syndrome
}

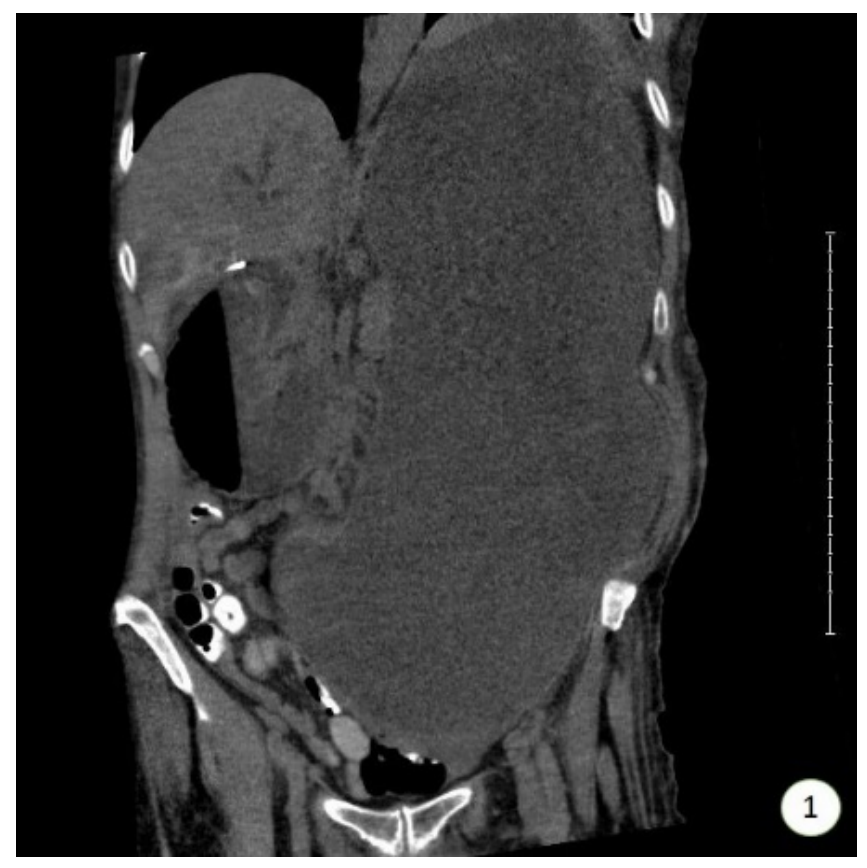

Figure 1. Massive dilation of the gastric body with extension into the pelvis.

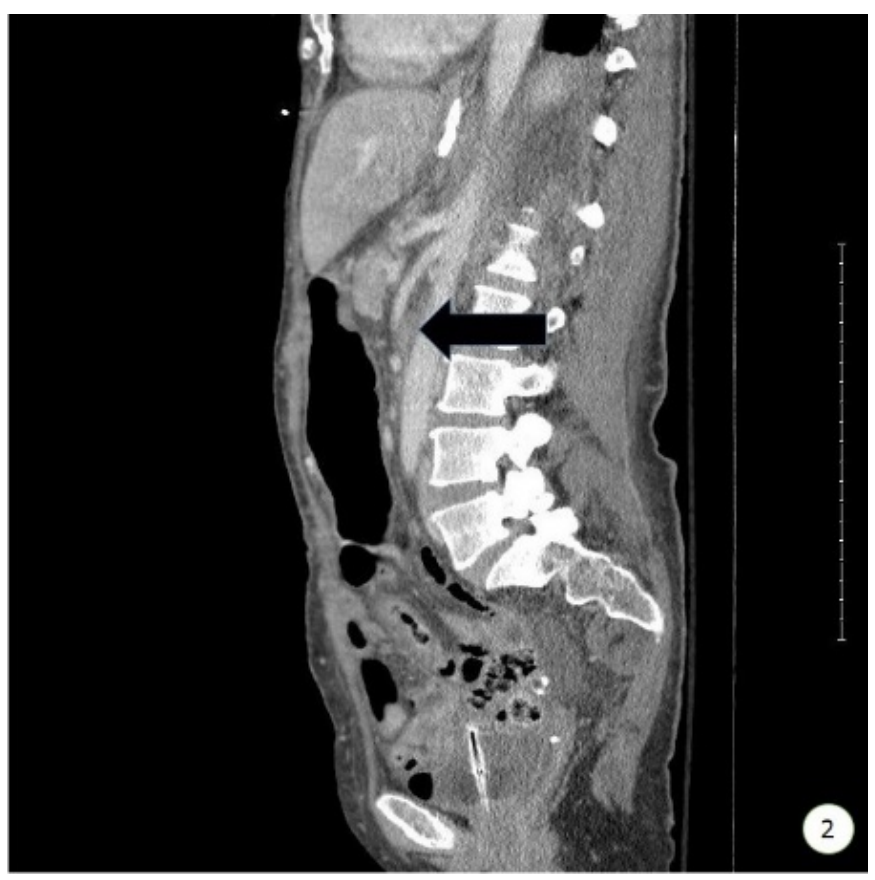

Figure 2. CTA demonstrating an acute aortomesenteric angle with the duodenum compressed. 


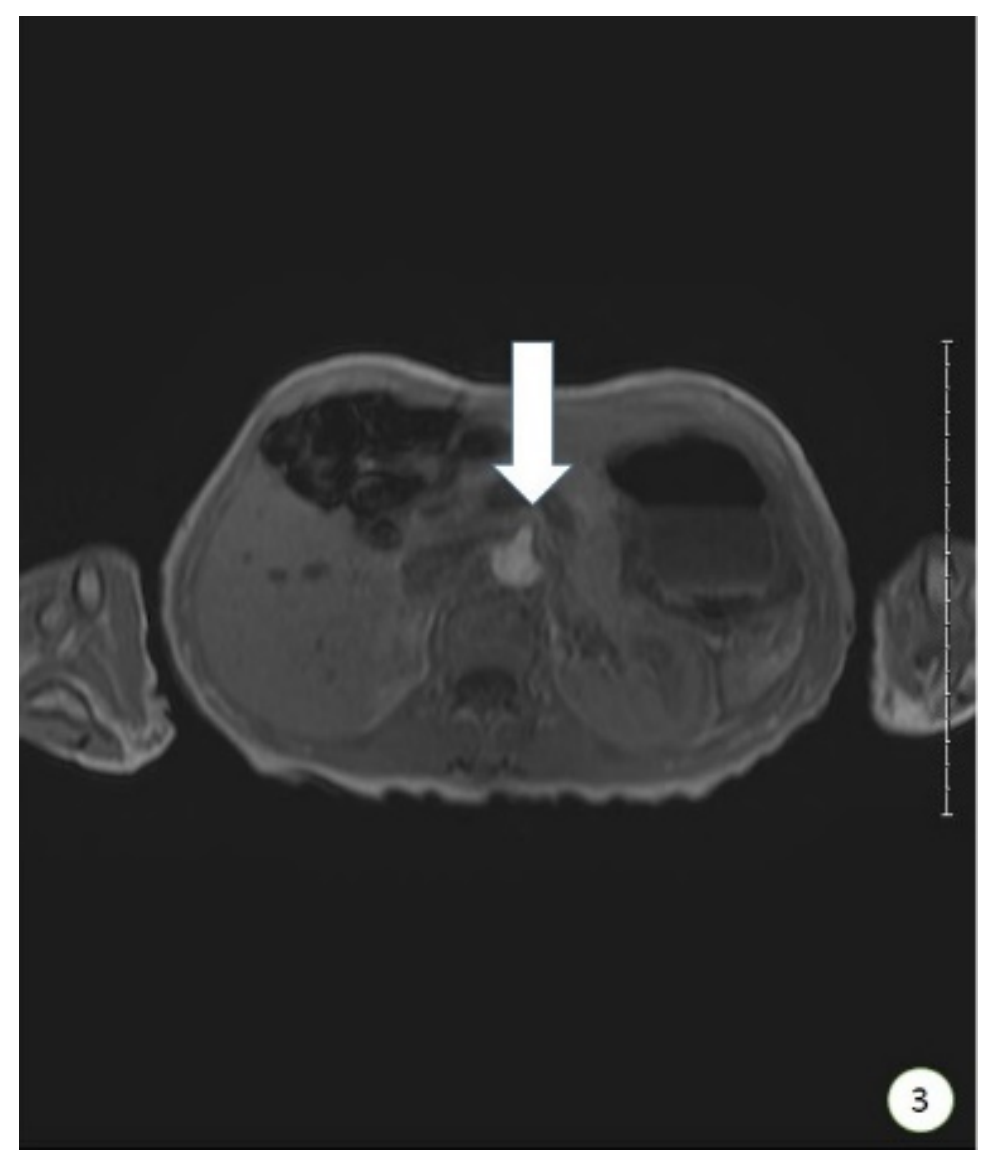

Figure 3. Contrast MRI with impingement of the third part of the duodenum by the superior mesenteric artery and abdominal aorta.

The patient was a 46 year-old woman admitted for accelerated hypertension. Several days into her hospital stay she reported new complaints of progressive abdominal pain, vomiting, and constipation. An abdominal radiograph confirmed severely dilated bowel and a subsequent CT scan of the abdomen was unable to identify a cause for bowel obstruction. Endoscopy was performed with successful entrance of the first part of the duodenum. MRI of the abdomen with contrast was ultimately able to delineate an obstruction of the third part of the duodenum between the superior mesenteric artery and the aorta.

Superior mesenteric artery syndrome is a rare but recognized cause for duodenal obstruction. Patients may present with intermittent or progressive epigastric pain, nausea with bilious vomiting, and early satiety. Medical management is largely conservative with gastric suctioning and pain management, with definitive treatment being surgical correction of the aortomesenteric angle.

Seth Assar, MD; Natasha Sharda, MD; Varun Takyar, MD; Bujji Ainapurapu, MD Department of Medicine at South Campus

University of Arizona

Tucson, Arizona 


\section{References}

1. Hines J, Gore R, Ballantyne G. Superior mesenteric artery syndrome. Diagnostic criteria and therapeutic approaches. Am J Surg. 1984;148:630-2. [CrossRef]

2. Felton BM, White JM, Racine MA. An uncommon case of abdominal pain: superior mesenteric artery syndrome. West J Emerg Med. 2012;13(6):501-2. [PubMed]

3. Baltazar U, Dunn J, Floresguerra C, Schmidt L, Browder W. Superior mesenteric artery syndrome: an uncommon cause of intestinal obstruction. South Med J. 2000;93(6):606-8. [PubMed] 